\title{
EXIGÊNCIA PARA O DESENVOLVIMENTO DAS NOSSAS INDÚSTRIAS: O ENSINO TÉCNICO NO CONTEXTO DA LEI ORGÂNICA DO ENSINO INDUSTRIAL
}

\author{
Mário Lopes Amorim \\ Universidade Tecnológica Federal do Paraná - Brasil.
}

Resumo

O objetivo desse artigo é compreender a criação dos cursos técnico-industriais de nível médio no Brasil, a partir da Lei Orgânica do Ensino Industrial (1942), em um contexto de rápida industrialização do país, levando em conta os interesses da classe empresarial e do Estado. Utiliza-se como referência alguns artigos sobre a organização didático-pedagógica dos referidos cursos, publicados na revista Labor, da Escola Técnica de Curitiba. Procura-se identificar as influências de diversas concepções pedagógicas para o ensino profissional presentes na estruturação desse ramo de ensino, bem como destaca a importância conferida ao ensino técnico na preparação e conformação de mão-de-obra qualificada.

Palavras-chave: ensino industrial, cursos técnicos, período Vargas, revista Labor.

\section{REQUIREMENT FOR THE DEVELOPMENT OF OUR INDUSTRIES: TECHNICAL EDUCATION IN THE CONTEXT OF THE ORGANIC LAW OF INDUSTRIAL EDUCATION}

\begin{abstract}
The aim of this paper is to understand the creation of industrial-technical courses average in Brazil, from the Industrial Organic Law of Education (1942), in a context of rapid industrialization of the country, taking into account the interests of the entrepreneurs and of the State. Uses as a reference a few articles on the pedagogical-didactic courses of these, published in Technical School of Curitiba's Labor magazine. Seeks to identify the influences of various pedagogical concepts for vocational education, present in the structure of this modality of education. Stresses the importance given to technical education in the preparation and formation of skilled labor.

Key-words: industrial training, technical courses, Vargas period, Labor magazine.
\end{abstract}




\section{REQUISITOS PARA EL DESARROLLO DE NUESTRAS INDUSTRIAS: EDUCACIÓN TÉCNICA EN EL MARCO DE LA LEY ORGÁNICA DE EDUCACIÓN INDUSTRIAL}

\section{Resumen}

El propósito de este artículo es comprender la creación del nivel medio de los cursos de técnico industrial en Brasil, desde la Ley Orgánica de Educación Industrial (1942), en un contexto de rápida industrialización del país, teniendo en cuenta los intereses de la clase empresarial y del Estado. Se utiliza como referencia algunos artículos sobre la organización didáctica y pedagógica de estos cursos, publicado en la revista Labor, de la Escuela Técnica de Curitiba. Busca identificar las influencias de diversos conceptos pedagógicos para la formación profesional en la estructuración de esta rama de la educación, así como destaca la importancia dada a la enseñanza técnica en la preparación y en la conformación de la fuerza de trabajo calificada.

Palabras-clave: la formación industrial, cursos técnicos, el período de Vargas, la revista Labor.

\section{EXIGENCE POUR LE DÉVELOPPEMENT DE NOS INDUSTRIES: ENSEIGNEMENT TECHNIQUE DANS LE CONTEXTE DE LA LOI ORGANIQUE DE L'ENSEIGNEMENT INDUSTRIEL}

\section{Résume}

L'objectif de cet article est de comprendre la création des cours de techniques industrielles du niveau moyen au Brésil, de la Loi Organique de l'Enseignement Industriel (1942), dans un contexte d'industrialisation rapide du pays, en tenant compte des intérêts des entrepreneurs et de l'État. II est utilisé comme référence quelques articles concernant sur l'organisation didactique et pédagogique de ces cours, publiée dans la revue Labor, de l'École Technique de Curitiba. Cherche à identifier les influences des diverses conceptions pédagogiques pour la formation professionnelle dans la structuration de cette modalité de l'éducation, ainsi que souligne l'importance accordée à l' l'enseignement technique dans la préparation technique et la conformation de la main-d'œuvre qualifiée.

Mots-clé: formation industrielle, cours techniques, la période de Vargas, le magazine Labor. 


\section{Introdução}

ste artigo tem por objetivo fazer uma análise da criação dos cursos técnicos de 2을 Ciclo, surgidos com a Lei Orgânica do Ensino Industrial, decreto lei $n$. 4.073, de 30 de janeiro de $1942^{1}$, após um longo debate havido durante a década de 1930 a respeito das finalidades do ensino profissional no Brasil, num momento em que, gradativamente, a indústria se torna cada vez mais presente no cenário econômico do país. A discussão a respeito da orientação pela qual deveria caminhar tal modalidade de ensino culmina com a edição da referida legislação, que estabelece as bases que irão reger o recém-criado Ensino Técnico-Industrial.

O texto tem a preocupação de pautar os pressupostos teóricos que serviram de base para os novos cursos técnicos, utilizando como documento alguns textos elaborados por professores da Escola Técnica de Curitiba e publicados na revista Labor ${ }^{2}$. Na análise desses textos procurou-se reconhecer as matrizes didático-pedagógicas que nortearam sua produção e que visavam a estabelecer uma determinada conformação para os cursos de $2^{\circ}$ Ciclo, tanto no âmbito da aprendizagem, quanto no disciplinar.

\section{Os anos 1930 e as alterações no ensino profissional}

A década de 1930 trouxe consigo uma série de transformações para a sociedade brasileira. Além do fim do predomínio das oligarquias paulista e mineira, depostas com a Revolução de 1930, a economia brasileira foi marcada pela crescente presença da indústria, que experimentou um período de expansão. Se a crise de 1929 provocou uma queda na produção industrial, a partir de 1933 verificou-se o início da recuperação da economia brasileira a partir do crescimento industrial. (Fonseca, 1989). Foi a partir de momento que a indústria assumiu o lugar agente principal do processo de expansão da economia:

a grande mudança que se deu, após 1930, foi que o poder passou a dar máxima prioridade ao desenvolvimento do mercado interno, ao crescimento 'para dentro', adotando uma estratégia em que a industrialização aparece como instrumento para tornar a economia nacional o menos dependente possível do mercado mundial. (Singer, 1984, p. 218)

A característica marcante da industrialização no período foi a presença do Estado como principal agente do processo, seja no planejamento, seja no investimento industrial. A atuação do Estado consistia na implantação do setor de bens de produção, a fim de que o processo de substituição de importações fosse coroado de êxito. Embora não dispusesse de capital suficiente para o investimento em todos os setores da indústria de base e dependesse em alguns deles da importação, contou com o amplo apoio do empresariado nacional. Concomitantemente, o Estado passou a ter um papel fundamental

${ }^{1} \mathrm{O}$ decreto-lei n. 4.073 estabelecia que o ensino industrial seria de nível médio, sendo dividido em dois ciclos: o $1^{\circ}$ Ciclo, composto pelos cursos industrial básico, artesanal, de mestria e de aprendizagem; destes, apenas o primeiro efetivou-se, tendo duração de quatro anos em regime seriado. O 20 Ciclo era composto pelos cursos técnicos e cursos pedagógicos, sendo que os primeiros tinham três anos de duração. Vale ressaltar que compunham um sistema paralelo ao Ensino Secundário.

2 Labor foi publicada entre abril de 1940 e novembro de 1947, num total de 19 números, sem uma periodicidade específica. Para maiores detalhes, ver Amorim (2003).
Hist. Educ. [Online]
Porto Alegre
v. 17
ก. 41
Set./dez. 2013
p. $123-138$ 
no controle da crescente classe operária, como demonstra a legislação trabalhista do período.

Nesse contexto está clara a importância da burguesia industrial em tal processo, pois, embora não possa ser considerada como classe hegemônica, sem dúvida será a grande beneficiária dos investimentos estatais no setor secundário realizados durante o período:

Ao mesmo tempo em que havia áreas de conflito na relação entre os empresários e o Estado em fins da década de 1930, havia uma percepção clara entre eles da necessidade de apoiar um Estado intervencionista, particularmente em vista da incapacidade dos empresários de lidarem com as esferas-chave de sua atividade, tais como o controle da classe operária e a integração do mercado. [...] As elites industriais passaram de um modelo relativamente descentralizador no início da década de 30 para um modelo altamente centralizador à época do Estado Novo, que eles finalmente apoiaram, tendo em vista a necessidade de manutenção do capitalismo industrial. Nesse sentido, enfatizariam claramente a noção de que as alianças não poderiam ser quebradas em detrimento da estabilidade e continuidade do sistema. (Boschi, 1979, p. 72)

O final dos anos 1920 e a década de 1930 marcam o predomínio das idéias de racionalização para todas as esferas sociais. Disciplinar para o trabalho e pelo trabalho: eis a palavra de ordem, veiculada como o discurso de uma elite ilustrada, explicitado no Inquérito Educacional de $1926^{3}$, mas que tomou conta do todo social.

A questão do controle operário é considerada como de fundamental importância (Weinstein, 2000), o que explica toda a série de procedimentos adotados quanto às limitações impostas à imigração, bem como às iniciativas de difusão dos pressupostos de racionalização científica, tanto no setor fabril, como no educacional, principalmente no ensino profissional. A criação do Instituto de Organização Racional do Trabalho - Idort -, em 1931, tinha como objetivo a maior difusão possível das idéias tayloristas, tarefa facilitada pela nomeação de um de seus líderes, Armando Salles de Oliveira, como interventor federal no Estado de São Paulo. Em relação ao ensino profissional, este teve importância decisiva na criação do Centro Ferroviário de Ensino e Seleção Profissional, em 1934, que serviu de modelo para a estruturação do Senai em 1942 (Moraes, 2003).

O projeto de reestruturação social, que investiu na disciplinarização das classes baixas pelo trabalho, apostou na escola como instrumento privilegiado. Tal situação foi atingida com a criação do Senai e com a Lei Orgânica do Ensino Industrial, ambas de 1942. Trata-se da constituição de uma mão-de-obra mais qualificada, com uma aprendizagem básica em escolas controladas pelos empresários, no caso do Senai, e da constituição de uma parcela de técnicos de melhor formação, responsáveis por um importante trabalho de ligação entre os operários e os engenheiros no processo industrial.

Ao longo da década de 1930 o Estado tomou uma série de medidas a respeito da educação profissional. Em 1931 foi criada a Inspetoria do Ensino Profissional Técnico, ligada ao também recém-criado Ministério da Educação e Saúde Pública, que passou a

${ }^{3}$ O Inquérito Educacional de 1926, dirigido por Fernando de Azevedo, foi uma iniciativa do jornal O Estado de São Paulo com o objetivo de fazer um levantamento da situação da instrução pública de São Paulo, como parte de uma campanha do jornal por uma reforma educacional no estado. Em 1925, procedeu-se a uma reforma do ensino em São Paulo, considerada retrógrada por Fernando de Azevedo, um dos expoentes dos liberais. Para maiores detalhes, ver Moraes (2003, p. 228-249).
Hist. Educ. [Online]
Porto Alegre
v. 17
n. 41
Set./dez. 2013
p. $123-138$ 
controlar as Escolas de Aprendizes Artífices. Em 1934 a Inspetoria foi transformada em Superintendência do Ensino Profissional, com o objetivo de expansão e organização desse tipo de ensino. Nesse mesmo ano foi criada, pelos ministérios do Trabalho e da Educação, uma Comissão Inter-Ministerial com o objetivo de elaborar um projeto para a formação profissional. A Superintendência do Ensino Profissional, por sua vez, foi extinta em 1937 e substituída pela Divisão do Ensino Industrial, subordinada ao Departamento Nacional de Educação. Também as Escolas de Aprendizes Artífices passaram à denominação de Liceus Industriais. Como se pode verificar, as atenções estão voltadas para o ensino profissional nesse momento, não somente pelas várias tentativas de organização e sistematização, mas, principalmente, pelo fato de o Brasil passar por um período de expansão industrial. Significa dizer, também, que está em crescimento a demanda por trabalhadores mais bem qualificados e que se buscava um caminho para reformarem-se as instituições que ministravam tal modalidade de ensino,

levando em consideração que o ensino nas escolas de aprendizes artífices estava restrito apenas à aprendizagem das profissões elementares, e que a evolução das indústrias no país já exigia um operariado com conhecimentos especializados e de nível superior ao do ensino primário. (Fonseca, 1961, v. 1, p. 208)

A respeito das preocupações do governo Vargas com esse ramo de ensino, Célio da Cunha (1981, p. 118) afirma que

entre as intenções educacionais de Getúlio, o ensino profissional tinha absoluta primazia, prioridade que sempre defendeu e pela qual lutou. A bandeira do ensino profissional recebe destaque na maioria de seus pronunciamentos. Parece ter sido, em matéria de educação, o único ideal realmente abraçado por Vargas.

Tal pensamento é também compartilhado por Pedro Cezar Dutra Fonseca:

Na visão de Vargas, [...] o problema educacional estava intimamente ligado ao trabalho; o educando era visto sobretudo por suas potencialidades com respeito ao trabalho futuro. A criação da riqueza dependia da produtividade, que se vinculava à qualificação e às condições físicas do trabalhador. Este era visto como capital humano, como evidencia a seguinte afirmação de Vargas: "Precisamos pôr em execução um plano completo de saneamento rural e urbano, capaz de revigorar a raça e melhorá-la como capital humano aplicável ao aproveitamento inteligente das nossas condições excepcionais de riqueza". Considerando viver-se na época do predomínio da máquina, alertava Vargas que esta exigia trabalho cada vez mais qualificado, daí o ensino profissional e técnico dever der levado ao extremo das possibilidades. (1989, p. 233)

Com o advento do Estado Novo e a outorga da Constituição de 1937, verificamos o quanto o ensino profissional era de fato relevante para Getúlio Vargas. No art. 129 a referida Constituição estabeleceu que

o ensino pré-vocacional e profissional destinado às classes menos favorecidas é, em matéria de educação, o primeiro dever do Estado. Cumpre-lhe dar execução a esse dever, fundando institutos desse tipo de ensino e subsidiando os de iniciativa dos Estados, dos Municípios e dos 
indivíduos ou associações particulares e profissionais. (Apud Fonseca, 1961, v. 1, p. 210)

Portanto, pela primeira vez tratava-se do ensino profissional numa Constituição. De acordo com Fonseca (1961), desde 1932 as dotações orçamentárias para essa modalidade de ensino aumentaram gradativamente em números absolutos e, em 1937, quase que dobram em relação ao ano anterior passando, a partir daí, a apresentarem um crescimento significativo até 1940.

Além do desenvolvimento industrial, a década de 1930 foi marcada por uma expansão no ensino industrial, tanto no número de matrículas, quanto no número de unidades escolares. Lucília Machado (1989) constata

uma modificação na participação do ensino industrial de $7,4 \%$ para $14,0 \%$, no conjunto do ensino médio, o que equivale a um crescimento de $335 \%$ entre 1935 e 1945. Neste sentido, o crescimento das matrículas no ensino industrial ultrapassa em muito a média geral de crescimento das matrículas no ensino médio, que foi de $129 \%$ no mesmo período. (p. 38)

Segundo essa autora, o número de matriculados no ensino industrial era de 15.035 alunos em 1935 e passou para 65.485 em 1945. Nesse sentido, tal expansão procura acompanhar o crescimento industrial do período: em 1940 havia 49.418 estabelecimentos fabris com 781.185 trabalhadores. Já em 1950 eram 89.086 indústrias que empregavam 1.256.807 trabalhadores (Dowbor, 1982). Apesar da expansão conhecida pelo ensino industrial no período, os números da indústria demonstram que a quantidade de alunos egressos das escolas industriais e técnicas era insuficiente para atender a demanda fabril.

O governo Vargas apostou na industrialização como o caminho para a superação da crise econômica. Como o empresariado industrial ainda não apresentava as condições necessárias para bancar o projeto de industrialização, o Estado atuou neste sentido. Apesar disso, o empresariado desempenho ações fundamentais no processo industrializante, apresentando ao Estado a sua agenda para a concretização do processo:

A primeira demanda aponta para a integração do mercado interno transformando sua base local numa base nacional. A segunda indica uma tendência embrionária para o estabelecimento de negociações com o Estado numa base corporativista para a discussão e decisão a respeito da capacidade extrativa do Estado. A terceira chama a atenção para o problema da capitalização das empresas industriais facilitando sua expansão. Finalmente, o controle da força de trabalho pelo Estado é visto como um passo necessário. (Boschi, 1979, p. 67)

Nesta declaração de intenções, chama-nos a atenção, principalmente, a última demanda. Embora não se possa considerar, nesse contexto, a burguesia industrial como a classe que determina quais políticas públicas deviam ser priorizadas, está fora de dúvida o seu apoio a toda e qualquer iniciativa estatal que vesse a lhe favorecer. Se a intenção do governo Vargas era o controle dos trabalhadores pela disciplina do trabalho, certamente teria todo o apoio por parte do empresariado. Pode-se destacar o interesse dos industriais pelo ensino profissional, a ponto de buscarem o controle sobre a formação de mão-de-obra especializada. 
Além da formação de mão-de-obra, o interesse empresarial em relação ao ensino profissional também se direcionou para estratégias de paz social e racionalização do trabalho. Isto fazia com que cada vez mais aumentasse a preocupação com este tipo de ensino. O setor empresarial tomou para si a formação mais aligeirada de operários, para atender as demandas emergenciais do setor industrial, com o Senai, mas não abriu mão de que o governo federal mantivesse instituições de ensino para a formação de técnicos com uma formação mais completa e abrangente. Estes deveriam ser os

profissionais de grau médio, intermediários entre o operário e o engenheiro e cujas funções consistem na condução do trabalho, na chefia de seções industriais e de oficinas, na elaboração de desenhos, na execução de fiscalização e do controle da produção e em trabalhos de ensaio e de laboratórios. (Carone, 1977, p. 294)

Assim, no âmbito da Lei Orgânica do Ensino Industrial, a concepção adotada para as agora denominadas escolas técnicas ${ }^{4}$ é a de serem formadoras de uma elite de técnicos necessários para a indústria, com formação direcionada para sua disciplinarização, com vistas a paz social pretendida pelo Estado Novo, sem prescindir de princípios da racionalização científica.

\section{O técnico: a nova exigência para o desenvolvimento das nossas indústrias}

A Lei Orgânica do Ensino Industrial estabeleceu a organização do ensino industrial como um sistema, isto é,

o conjunto de estabelecimentos que ministram ensino de um determinado tipo, seguindo uma mesma legislação que lhe dá os objetivos e os traços fundamentais da organização dos recursos educacionais para atingi-los; são coordenados, supervisionados ou fiscalizados por um mesmo órgão administrativo. (Cunha, 2000, p. 120)

A principal motivação para a organização deste sistema foi a necessidade de suprir a crescente demanda por trabalhadores mais qualificados no âmbito do setor secundário da economia. Célio da Cunha (1977, p. 55) destaca que "a conjuntura econômica decorrente da segunda guerra mundial criou condições para a organização do ensino técnico industrial, através do aumento provável da demanda de técnicos”, e enumera razões para este crescimento: o aumento da produção industrial, acompanhado pelo crescimento da oferta de empregos; o uso racional da mão-de-obra qualificada; e a necessidade de substituição de técnicos importados.

Assim, o processo de desenvolvimento industrial pelo qual passou o país, com a segmentação do mercado de trabalho, levou à hierarquização do trabalho e à necessidade de um pessoal com uma formação baseada na racionalização científica, com o objetivo de aumentar a produtividade. Há uma insistência na necessidade do técnico, neste caso definido como trabalhador com uma "função específica na empresa ou entidade em que trabalha" (Cunha, 2000, p. 112). Para um maior esclarecimento destas funções, tome-se como referência a resolução n. 51, de 25 de julho de 1946, do Conselho

\footnotetext{
${ }^{4}$ A partir da Lei Orgânica do Ensino Industrial, os Liceus Industriais passam a denominar-se Escolas Técnicas, passando a ofertar o $1^{\circ}$ e $02^{\circ}$ Ciclos do Ensino Industrial; as instituições que ofertassem apenas 0 $1^{\circ}$ Ciclo passariam a ser denominadas Escolas Industriais. Hist. Fduc [Online] $\quad$ Porto Alegre $\quad$ v. 17

ก. 41 Set./dez. 2013 p. $123-138$
} 
Federal de Engenharia, Arquitetura e Agronomia (CFEA), que regulamentou a profissão de técnico industrial e estabeleceu suas atribuições:

conduzir trabalhos de sua especialidade, projetados e dirigidos por profissionais legalmente habilitados (de nível superior); projetar e dirigir trabalhos que não exigissem a responsabilidade de um engenheiro, desde que obtivessem autorização prévia do Conselho Regional de Engenharia; exercer a função de desenhista, na sua especialidade; projetar e dirigir trabalhos de sua especialidade em pontos do território nacional onde não houvesse engenheiros; exercer as funções de Auxiliar de Engenheiros nas repartições públicas, independentemente de prova de habilitação. (Ibid., p. 116)

Luiz Antonio Cunha (2000) conclui que os técnicos não passariam de meros auxiliares de engenheiros. Seja como for, a indústria brasileira era carente desse pessoal mais especializado e tratava-se de envidar esforços para formá-los de acordo com os parâmetros enumerados acima.

Alguns artigos da revista Labor contribuem para definir o tipo de formação que o técnico industrial devia receber nas escolas técnicas. Inicialmente, ressalta-se a importância dos cursos técnicos para o desenvolvimento do país. Ao celebrar a criação dos referidos cursos na Escola Técnica de Curitiba, justifica-se no editorial do n. 10:

Tendo por escopo principal preparar e orientar, de maneira prática e segura, a mocidade brasileira, no sentido de fornecer-lhe os conhecimentos profissionais, a fim de que em futuro próximo tenhamos técnicos em número suficiente às necessidades oriundas do nosso desenvolvimento industrial, nada falta à Escola Técnica, para realizar tão alto e patriótico desideratum. Bastaria esse fato, eloqüente por si mesmo, para se ter uma idéia do programa sabiamente confeccionado para o funcionamento regular e metódico dos Cursos Técnicos, destinados ao preparo intelectual e profissional dos que terão de prestar os seus serviços à industrialização do nosso País. [...] Construir as máquinas, pô-las em movimento, saber manejá-las com eficiência, tirar o melhor resultado das mesmas, eis o que o Brasil espera de seus filhos, eis o que ensina a Escola Técnica de Curitiba, colméia formadora de hábeis profissionais, assegurando a estes o trabalho compensador e ao País os recursos de que precisa para o seu progresso industrial, capaz de determinar a nossa independência econômica. (Nossa..., 1943, p. 1)

Nota-se o caráter de urgência na preparação desses técnicos, pois deles dependia o progresso industrial do Brasil. A partir desse pressuposto inicial, toma-se como base o programa do curso Técnico de Eletrotécnica para se analisar como acontecia a transmissão do conhecimento em tais cursos ${ }^{5}$. Tal programa foi elaborado pelo professor Frederico Mattmüller, da Escola Técnica Nacional, em 1943, e estendido a todas as escolas técnicas de âmbito federal. Em princípio, o programa definia que

a finalidade de formar estes profissionais aptos ao exercício dos ofícios mencionados será atingida pelo ensino teórico, das Aplicações de Eletricidade, do Desenho Eletrotécnico e da prática de oficina. [...] As disciplinas de Cultura Geral (Português, Inglês ou Francês, Matemática,

\footnotetext{
${ }^{5} \mathrm{~A}$ escolha deste programa de curso deve-se ao fato de ser o único documento que encontramos a respeito do processo ensino-aprendizagem dos cursos técnicos instituídos com a Lei Orgânica do Ensino Industrial. \begin{tabular}{|l|l|l|l|l|l|}
\hline Hist. Educ. [Online] & Porto Alegre & v. 17 & n. 41 & Set./dez. 2013 & p. 123-138
\end{tabular}
} 
Física, Química, História e Geografia) deverão concorrer para elevar o valor humano do Técnico. A educação Física completa a formação da personalidade. Eis um programa vasto e importante considerando bem todas as faculdades do jovem Técnico, a ser desenvolvidas vantajosamente para seu trabalho, como para seu aspecto social. O problema principal, que abrange todos os assuntos desta formação técnica, consiste na soma dos conhecimentos técnicos a obter do aluno. (Mattmüller, 1944, p. 15)

Chama a atenção o fato da formação profissional do técnico só ser considerada a partir da chamada parte técnica, cujas disciplinas específicas teriam por finalidade capacitar o aluno a "projetar, desenhar, calcular, sobreviar, e examinar os trabalhos de sua especialidade, que o técnico escolheu depois de terminado o Curso" (lbid., p. 15). A cultura geral seria apenas uma acumulação de conhecimentos nas disciplinas acima citadas. Ambas as partes, somadas, capacitariam o aluno a se tornar um profissional qualificado, pois assim se obteria uma força de trabalho mais eficiente e produtiva, capaz de colaborar para o desenvolvimento do país. O Estado passou a intervir na educação a fim de atender as necessidades dos diferentes setores da indústria. Logo, não bastava a pura e simples expansão dos sistemas educacionais, mas "tornar-se-ia necessário dar determinados tipos de educação a quantidades definidas de componentes atuais e futuros das forças de trabalho" (Machado, 1989, p. 106).

No que concerne à parte didático-pedagógica, pode-se depreender que havia uma fusão de diferentes metodologias de ensino com vistas à formação do técnico. Em primeiro lugar evidencia-se a influência do método intuitivo, praticado na Escola de Aprendizes Artífices do Paraná ${ }^{6}$ desde a sua instalação até o final da gestão de seu primeiro diretor, Paulo Ildefonso D’Assumpção. Dentre os elementos que nos permitem tal constatação encontramos a defesa da interação entre a teoria e a prática, quando se especifica a organização do curso: "O Ensino teórico e o ensino prático apoiar-se-ão sempre um no outro" (Mattmüller, 1944, p. 16).

Ao tratar da parte teórica, é destacada a importância de sua vinculação com a prática:

Iniciar-se-á com o ensaio. Lembramo-nos das nossas aulas de Física, nas quais o Professor ficou nos entusiasmando de prazer e de descobertas notáveis! Matéria sublime dos eletrônios invisíveis! Procurar, experimentar, ilustrar, explicar, calcular, elaborar... atividades das mais elevadas! Feliz o aluno que pode seguir tal série de estudos teóricos! A experiência junta-se a explicação teórica e o desenvolvimento da fórmula básica, apoiada pelo diagrama e pelo esquema. O senso didático do professor, o giz no quadro negro, obterão máximos triunfos! (Ibid., p. 16)

Outro ponto a ser destacado é o ensino partindo dos conteúdos mais simples para os mais complexos. A descrição da parte prática do programa é reveladora:

A parte prática consiste em trabalhos fundamentais de bancada; além disso, de manufatura de ferramentas simples. Seguem então trabalhos nas máquinas operatrizes (furador, torno e politriz). As especialidades elétricas de Acumuladores, Eletro-Química, Instalações e Ajustagem (consertos e

\footnotetext{
${ }^{6}$ Denominação da Escola Técnica de Curitiba desde a sua criação em 1909 até 1937. \begin{tabular}{|l|c|c|c|c|c|}
\hline Hist. Educ. [Online] & Porto Alegre & v. 17 & n. 41 & Set./dez. 2013 & p. 123-138
\end{tabular}
} 
enrolamentos). Construções simples e sobressalentes concluem a seriação da prática. (Ibid., p. 16)

Mesmo a parte de aplicações elétricas não devia, em nenhum momento, desvincular-se da parte teórica:

Em paralelo com a teoria tratam-se as Aplicações elétricas. Nos livros usuais esta parte é geralmente tratada como matéria anexa, quando devia constituir o ponto principal. A maneira de empregar um princípio elétrico num aparelho ou numa máquina será esclarecida dentro da diversidade das várias e numerosas construções habituais. (Mattmüller, 1944, p. 16)

Chama a atenção outra característica do método intuitivo, que é a crítica aos livros didáticos, exatamente por tratar a prática separadamente da teoria. Também não é gratuita a citação, por parte do professor Mattmüller, de Pestalozzi, ao enfatizar a necessidade do professor aproximar-se do objeto de análise, mesmo tendo que recorrer a fotografias e filmes para tanto, além de excursões à fábricas, para que ficasse evidenciado o ponto de partida da aprendizagem pela observação, caracterizando-se um ensino de natureza demonstrativa.

Nota-se a influência das ideias de Victor Della Voss, diretor da Escola Imperial Técnica de Moscou, apresentadas na Exposição Internacional de Viena em 1873. ${ }^{7}$ Aqui já aparecia a associação das práticas de oficinas com as disciplinas teóricas, bem como o início do aprendizado pelas partes mais simples para, gradativamente, se chegar às etapas mais complexas, objetivando-se que o aluno conhecesse todas as fases do processo de elaboração das peças. Destacamos, ainda, a sugestão de se trabalhar com coleções de instrumentos e modelos:

A escola é o lugar do trabalho técnico, onde o aluno, rodeado de todos os meios de instrução, respirando a atmosfera técnica, deve especialmente aprender. [...] No lado construtivo temos uma coleção de modelos eletrotécnicos, desde peças simples até conjuntos completos. O aluno pode instruir-se vantajosamente com as construções práticas, já experimentadas e em uso. [...] Conjuntos esquemáticos para ligações especiais, aproveitavelmente montados em tábuas de tamanho normal, e tábuas de materiais, compostas sistematicamente, servirão igualmente ao Ensino eficaz. (lbid., p. 16)

Tais modelos serviriam, tanto para facilitar a aprendizagem, quanto para impor padrões a serem utilizados para a elaboração das instalações elétricas. Assim,

com esse método de ensino, Della Voss visava, portanto, satisfazer às seguintes condições: diminuir o tempo de aprendizagem; controlar, mediante procedimentos simples e rápidos, o avanço dos alunos nos estudos práticos e, finalmente, dar ao ensino técnico um caráter sistemático, capaz de fazer dele um novo meio de adquirir conhecimentos úteis. (Moraes, 2003, p. 383)

Ao lado das características do método intuitivo e da ascendência das concepções de Della Voss, encontramos elementos do método de industrialização, elaborado e

\footnotetext{
${ }^{7}$ Ver Moraes (2003, p. 383) e Queluz (2000, p. 137).
} 
implementado por João Luderitz ${ }^{8}$ para o Instituto Técnico-Profissional de Porto Alegre. Destacamos a importância da interligação entre ensino prático e teórico, procedimento evidenciado também pelo método intuitivo. Concomitantemente, Roberto Mange ${ }^{9}$ iniciava a aplicação das séries metódicas na Escola Profissional de Mecânica do Liceu de Artes e Ofícios de São Paulo. A série metódica consiste em usar o material adequado para a produção

dentro de uma sequência de operações bem planejadas, capaz de produzir o melhor trabalho, no menor espaço de tempo e com o menor desperdício de material. Ensinar é a mesma coisa. Os materiais ou os elementos obtidos por intermédio da análise do ofício devem ser cuidadosamente organizados e dispostos a fim de que a aprendizagem possa ser feita no menor prazo possível, com o mínimo de confusão e com o menor esforço por parte do aluno. A disposição da matéria a ser ensinada, dentro de um plano exeqüível, é o que se chama uma série metódica. (Bollinger; Weaver, 1950, p. 18)

No programa do curso de Eletrotécnica que está sendo analisado, observamos a presença das folhas de instrução. Estas deveriam servir de auxílio para "os trabalhos a serem feitos em casa, [que] com ajuda das folhas de ensino, servirão para repetição ou recordação". (Mattmüller, 1944, p. 17). Da mesma forma, o professor utilizará "folhas de ensino, contendo apenas os resultados dos processos, as fórmulas e os cálculos aplicados, servindo estas folhas para elaborar os exercícios, e substituir o grande livro técnico". (lbid., p. 17). A inspiração dessa metodologia é a organização racional do trabalho, que postulava a necessidade das "folhas diárias de trabalho, que indicam claramente as operações e a sequência de fabricação com que devem ser executadas" (Pagano, 1942, p. 165). Logo,

tanto nas oficinas escolares como nas das indústrias seguem-se os mesmos métodos: ordens gerais de trabalho, ordens individuais de trabalho, esquemas, cópias-azuis, traçados, etc. As folhas de tarefa, como qualquer outra forma conveniente de fornecer informações e dados para o trabalho, devem ser usadas nas oficinas escolares. Um professor, por exemplo, pode preparar uma descrição para cada tarefa da série. Estas instruções por escrito indicariam o trabalho a ser executado, os passos a serem dados, as ferramentas e outras informações básicas para a realização da dita tarefa. Estas folhas de instrução, cujo propósito é descrever a tarefa a ser feita, incluem ainda, esquemas e desenhos dos processos de trabalho. Para as classes mais adiantadas a folha de instrução é semelhante à cópia-azul ou ao desenho usado nas oficinas mecânicas; pode ser semelhante às ordens individuais de trabalho que se usam nas oficinas de consertos de automóveis. Na maioria dos ofícios, as instruções para o trabalho devem ser pouco mais do que uma simples informação oral ou por escrito. (Bollinger; Weaver, 1950, p. 138-40)

${ }^{8}$ Diretor do Instituto Técnico-Profissional de Porto Alegre, Instituto Parobé, e, a partir de 1920, diretor do Serviço de Remodelação do Ensino Profissional Técnico do então Ministério da Agricultura, Indústria e Comércio. Mais tarde foi o primeiro diretor do Departamento Nacional do Senai.

${ }^{9}$ Criador da Escola Profissional Mecânica do Liceu de Artes e Ofícios de São Paulo, em 1923, além de membro do Idort, criador do Centro Ferroviário de Ensino e Seleção Profissional em 1934 e fundador e diretor do Senai em São Paulo até 1955.

Hist. Educ. [Online] Porto Alegre

v. 17

ก. 41

Set./dez. 2013

p. $123-138$ 
A preocupação com o alfabetismo técnico, isto é, com a necessidade que o aluno dominasse "quatro sistemas notacionais, seus vocabulários correlatos e suas gramáticas: expressão alfabética, notação científica, notação matemática e representação gráficoespacial" (Stevens apud Queluz, 2000, p. 12), aparecia no processo metódico do professor Mattmüller quando ele enfatiza que "cálculos desenvolvidos na forma puramente numérica ou com texto explicativo completam o ensino teórico na parte quantitativa. Esta arte de expressar representa uma linguagem mundial, a que o aluno se deve habituar e precisa ser cultivada" (Mattmüller, 1944, p. 16). O Desenho Técnico tinha um papel fundamental na estrutura do curso, pois este

faz uso das capacidades de imaginação e de construção. Aí mais uma vez tem o técnico uma linguagem universal para fixar, elaborar e comunicar a sua idéia técnica! Bem cultivado, chegar-se-á pelo desenho preparativoprojetivo-construtivo às plantas de disposição e de instalação. Os esquemas de ligação devem apresentar claramente às ligações internas dos circuitos. Procedendo assim, o aluno desenvolverá rapidamente esta faculdade elevada, do desenho técnico. (Ibid., p. 17)

De acordo com Carmen Sylvia Vidigal Moraes (2003),

a ênfase no ensino do desenho sugere o seu avanço como exteriorização e sistematização dos conhecimentos práticos, processo que ocorre simultaneamente ao parcelamento das tarefas e à desapropriação do saber do trabalhador. Cada vez mais o desenho, enquanto saber convencional representa uma ordem codificada, simbologia da violência expressa no trabalho dividido e hierarquizado, isto é, no trabalhador alienado. Por isso, seu uso como instrumento disciplinar instituidor da ordem no pensamento e nas mãos do trabalhador. (p. 384-385)

A avaliação seria o momento final desse processo metódico. Somente

a seriação: ensino-teoria-cálculo-laboratório-exercício vai aprofundar a noção, vai formar a concepção, associando-se com as concepções já existentes até a idéia final. As provas de exame sem esta formação metódica têm um valor reduzido; só podem demonstrar mais ou menos boa memória ou vivacidade intelectual. [...] Reunindo assim todos os esforços, procede a Escola à Prova Final. Não somente os conhecimentos e capacidades técnicas decidem, pois; está em jogo a própria personalidade do homem: Boa concepção, disposição, construção, cálculo, desenho, aplicação e adaptação às exigências práticas devem ser incentivadas. $O$ método antigo de questionar não pode dar um resultado razoável. Assim devem resultar a nota final e o diploma. (Mattmüller, 1944, p. 17)

Portanto, somente se esse modelo prévio fosse rigorosamente seguido o aluno teria condições de passar sem susto pela avaliação final e obter a formação de técnico. Tal procedimento objetivava a disciplinarização do trabalhador, que operaria sempre na mesma sequência, introjetando uma rotina no sentido de tornar-se uma mão-de-obra rápida e eficaz: "um corpo disciplinado é a base de um gesto eficiente" (Foucault, 1983, p. 139). Tais características seriam o diferencial dos técnicos em relação aos demais trabalhadores, isto é, uma mão-de-obra adequada à modernidade, representada pelo processo de industrialização e que, por ser detentora de conhecimentos específicos 
desse processo, estaria capacitada para desempenhar um papel fundamental no progresso do país.

Pode-se concluir, pela análise do texto do professor Mattmüller, que a metodologia de ensino dos cursos técnicos tinha influências variadas, tanto dos procedimentos utilizados desde a fundação da Escola de Aprendizes Artífices do Paraná, baseados no método intuitivo e nas suas conjugações com o sloyd, ${ }^{10}$ no caso do destaque dado ao caráter demonstrativo do ensino, implementado por seu primeiro diretor, até as diretrizes do Serviço de Remodelação do Ensino Profissional Técnico, chefiado por João Luderitz na década de 1920, que empreendeu uma série de reformas baseadas em suas experiências quando diretor do Instituto Parobé de Porto Alegre, onde se instaurou um método de industrialização fundamentado em ideias desenvolvidas na Europa e nos Estados Unidos, principalmente as de Victor Della Voss. Pode-se, ainda, mencionar a presença das concepções desenvolvidas no Liceu de Artes e Ofícios de São Paulo desde o início do século 20, cuja ênfase

significava priorizar a transmissão do conhecimento durante a prática profissional, de maneira a instruir fazendo. O aluno, admitido como simples aprendiz, se instruía observando o trabalho dos mestres ou realizando parte deles. Ao participar do conjunto da produção, podia conhecer todas as etapas de realização do objeto, o que lhe permitiria, no final do treinamento, situar-se em uma delas e transformar-se em um especialista, ou seja, em um operário efetivo ou artífice. (Moraes, 2003, p. 363)

Estão presentes também elementos das séries metódicas, que inspiraram a denominação do processo desenvolvido pelo professor Mattmüller. As séries são resultado dos trabalhos de Roberto Mange à frente da escola de Mecânica do Liceu de Artes e Ofícios de São Paulo e, posteriormente, do Centro Ferroviário de Ensino e Seleção Profissional de São Paulo - CFESP - e do Senai.

As disciplinas de cultura geral tinham a função de elevação do valor humano. Algumas delas, porém, eram consideradas como mais importantes pela sua aplicação ao trabalho dos técnicos, conforme o exemplo abaixo:

A Matemática faculta ao técnico, consciente do seu papel de obreiro inteligente e, portanto, capaz de realizar, de criar algo novo, uma atividade harmoniosa do cérebro e das mãos, em nada parecida com o cego automatismo ou com o deprimente servilismo a estagnante rotina, impotente para motivar e incrementar o mais leve progresso e semelhante ao instinto dos animais [...]. A Matemática, insistamos, põe nas mãos do técnico os mais poderosos recursos, de investigação e verificação, ao mesmo tempo que, de modo surpreendente, aguça-lhe a capacidade intelectiva e previsora.[...]. O ensino da Matemática para técnicos deve ser sistemático e lógico, visando decisivamente o desenvolvimento da inteligência e do raciocínio matemático; ao contrário, não deve ser ocasional nem empírico, com o mero caráter de um receituário ou de um formulário, para a resolução de casos concretos. (Freitas, 1945, p. 4)

${ }^{10} \mathrm{O}$ chamado sloyd educacional, de acordo com Pereira (2007, p. 70), corresponde a uma série de princípios para o ensino técnico, como por exemplo, a demonstração, a progressão do fácil para o difícil, e a ênfase nos trabalhos manuais e na precisão do acabamento.
Hist. Educ. [Online]
Porto Alegre
v. 17
ก. 41
Set./dez. 2013
p. $123-138$ 
Embora não haja nenhum texto específico na revista Labor, pode-se supor que as disciplinas das ciências exatas tinham tal direcionamento, uma vez que se tratava de cursos em que o conhecimento dos conteúdos de tais disciplinas era importante para a formação específica do técnico. A exceção que encontramos refere-se à Educação Física, mas a argumentação explicitada a seguir não deixa dúvidas quanto aos seus objetivos:

Nas escolas profissionais, merece a educação física especial atenção. Daí sairão os futuros operários técnicos especializados, que irão dar maior impulso às indústrias do país. Para isso é preciso que eles estejam técnica e fisicamente preparados, a fim de dar o máximo de rendimento com o mínimo possível de dispêndio e energia. Nas escolas industriais, a educação física tem por fim, assegurar e melhorar a saúde do futuro profissional, desenvolvendo e aprimorando as qualidades físicas, e estimulando o funcionamento dos órgãos. Visa ainda desenvolver, de maneira toda especial, certas qualidades físicas inerentes à profissão escolhida, para um maior rendimento do seu trabalho. (Bassoi, 1944, p. 14)

De acordo com a ocupação futura a ser exercida pelo técnico, este receberia determinado tipo de carga de exercícios físicos. Em suma, todo o processo descrito seria responsável pela formação da personalidade do futuro trabalhador. Somente com a instrução adequada o indivíduo estaria preparado para desempenhar um papel decisivo para a industrialização para o progresso do país.

\section{Considerações finais}

As transformações por que passava a estrutura econômica brasileira ao longo da década de 1930 foram muito significativas para as mudanças verificadas para o ensino profissional. Os processos produtivos introduzidos no país durante o período mencionado, aliados às dificuldades e restrições para a vinda de novos imigrantes, levaram o Estado e os industriais a se preocuparem com a formação de trabalhadores capacitados para a tarefa da industrialização. Se o empresariado assumiu a formação mais rápida e aligeirada, pelo Senai, o Estado promoveu, pela via do ensino técnico, a formação mais completa dos profissionais encarregados de servirem de intermediários entre os operários e os engenheiros, logo destacados como essenciais para o rápido progresso e industrialização do Brasil.

Assim, pode-se considerar que era o curso planejado para a criação de uma elite do trabalho por excelência, levando-se em conta também as funções que desempenharia no meio fabril. Também deve ser ressaltada a chamada formação geral, considerada fundamental a capacitação dos profissionais em preparação para dar sustentação ao desenvolvimento industrial do país. Para a delimitação dos conhecimentos e habilidades específicas dos técnicos, várias proposições para o ensino profissional dialogaram entre si, caracterizando uma ampla gama de influências para a definição do técnico de nível médio.

Mas não é só o aspecto profissional que deve ser considerado. De nada valeriam todos esses esforços se não fossem direcionados na constituição de um grupo de trabalhadores que deveria se pautar pelos pressupostos da racionalização científica. Logo, tanto para o Estado Novo, quanto para a classe empresarial, está claramente delineada uma concepção de mão-de-obra: capacitada e ordeira para permitir o salto do país rumo ao progresso. 


\section{Referências}

AMORIM, Mário Lopes. Alfabetizar e formar técnicos para as nossas indústrias: a revista Labor. In: QUELUZ, Gilson Leandro (org.). Tecnologia e sociedade: (im)possibilidades. Curitiba: Torre de Papel, 2003, p. 81-100.

BASSOI, Mario. A educação física nas escolas profissionais. Labor, Curitiba, n. 12, p. 1415, nov., 1944.

BOLLINGER, Elroy W; WEAVER, Gilbert G. Organização de séries metódicas. Rio de Janeiro: MEC/CBAI, 1950.

BOSCHI, Renato R. Elites industriais e democracia. Rio de Janeiro: Graal, 1979.

BRASIL. Decreto lei n. 4.073 - 30 jan. 1942. Estabelece as bases de organização e de regime do ensino industrial. Diário Oficial da União República dos Estados Unidos do Brasil, Rio de Janeiro, DF, 9 fev. 1942. Disponível em: <http://www010.dataprev.gov.br/ sislex/paginas/24/1942/4073.htm >. Acesso em: 23 ago. 2011.

CARONE, Edgard. O pensamento industrial no Brasil (1880-1945). Rio de Janeiro: Difel, 1977.

CUNHA, Célio da. Educação e autoritarismo no Estado Novo. São Paulo: Cortez/Autores Associados, 1981.

CUNHA, Luiz Antonio. O ensino profissional na irradiação do industrialismo. São Paulo: Unesp; Brasília: Flacso, 2000.

DOWBOR, Ladislau. A formação do capitalismo dependente no Brasil. São Paulo: Brasiliense, 1982.

FONSECA, Celso Suckow da. História do ensino industrial no Brasil. Rio de Janeiro: Nacional, 1961.

FONSECA, Pedro Cezar Dutra da. Vargas: o capitalismo em construção (1906-1954). São Paulo: Brasiliense, 1989.

FOUCAULT, Michel. Vigiar e punir. Petrópolis: Vozes, 1983.

FREITAS, Valdemiro Teixeira. Ensino da matemática nos cursos técnicos. Labor, Curitiba, n. 14 , set., 1945, p. 4-5.

MACHADO, Lucília R. de Souza. Educação e divisão social do trabalho. São Paulo: Cortez, 1982.

MATTMÜLLER, Frederico. Eletro-Técnica: a formação do eletro-técnico. Labor, Curitiba, n. 11, ago., 1944, p. 15-17.

MENDONÇA, Sonia R. Estado e economia no Brasil: opções de desenvolvimento. Rio de Janeiro: Graal, 1985.

MORAES, Carmen Sylvia Vidigal. A socialização da força de trabalho: instrução popular e qualificação profissional no estado de São Paulo (1873-1934). Bragança Paulista: Edusf, 2003.

NOSSA página. Labor, Curitiba, n. 10, maio, 1943, p. 1-2.

PAGANO, Mario. Princípios e técnica de racionalização industrial. São Paulo: Cruzeiro do Sul, 1942.

PEREIRA, Paulo Roberto Accorsi. O fazer e o aprender: uma interação singular na produção de mobiliário artístico da Escola de Artes e Ofícios de Amparo. São Paulo: 
Unesp, 2007. 163f. Dissertação (mestrado em Artes). Instituto de Artes, Universidade Estadual Paulista.

QUELUZ, Gilson Leandro. Concepções de ensino técnico na república velha (1909-1930). Curitiba: Cefet/PR, 2000.

SINGER, Paul. Interpretação do Brasil: uma experiência histórica de desenvolvimento. In: FAUSTO, Boris (dir.). História geral da civilização brasileira. Tomo III, 4. vol. São Paulo: Difel, 1984, p. 209-245.

WEINSTEIN, Barbara. (Re)formação da classe trabalhadora no Brasil (1920-1964). São Paulo: Cortez/CDAPH-Ifan-USF, 2000.

MÁRIO LOPES AMORIM tem doutorado em Educação pela USP. É professor no Programa de Pós-Graduação em Tecnologia da Universidade Tecnológica Federal do Paraná.

Endereço: Avenida Marechal Humberto de Alencar Castelo Branco, 444/450, casa 3, 82530-195 - Curitiba - PR - Brasil.

E-mail: marioamorim@utfpr.edu.br.

Recebido em 9 de setembro de 2012.

Aceito em 23 de abril de 2013. 